\title{
A ESCRITA COMO MORTALHA NUMA RUANDA DE "MÃES-CORAGEM"
}

MUKASONGA, Scholastique. A mulher de pés descalços. Tradução de Marília Garcia. São Paulo: Nós, 2017.160 p.

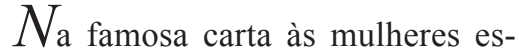
critoras do terceiro mundo, Glória Anzaldúa explicita algumas das constrições vivenciadas pelas mulheres de cor que fazem da palavra escrita uma forma de inscrição no mundo. O lançar-se no papel é compreendido como um desafio e um risco para essas mulheres que, contudo, são conclamadas poeticamente pela autora à escrita, na medida em que tal gesto circunscreve uma forma de (auto)reconhecimento e poder: "o que nos valida como seres humanos, nos valida como escritoras". ${ }^{1}$ Em seu apelo à expressão, a missiva remete a um conjunto plural e diverso de produções de mulheres que afrontaram os mecanismos históricos de interdição do acesso à literatura e por meio de seus textos constituíram espaços outros de existência, muitas vezes
\end{abstract}

1 Gloria Anzaldúa, "Falando em línguas: uma carta para as mulheres escritoras do terceiro mundo", Revista de Estudos Feministas, v. 8, n. 1 (2000), p. 234. em contraposição ao lugar subalternizado a elas relegado pelas forças hegemônicas globais. Problematizando as possibilidades de transfiguração que atuam como corolário de certa noção de autonomia da literatura, tais escritoras produzem obras nas quais, em consonância com a proposição de Anzaldúa, experiência pessoal, história e ficção constituem um amálgama de notável força estética.

Desde outro ponto do Atlântico Negro, chama atenção o contínuo que tais proposições estabelecem com a obra da brasileira Conceição Evaristo. Ela propõe um mergulho nos procedimentos que parecem tingir a escrita das mulheres negras em diáspora e depreende de tal produção o conceito de escrevivência. ${ }^{2}$ Marcando deslocamento

2 Para uma proposta de investigação mais detida de algumas das delimitações do conceito evaristiano de escrevivência, cf. Livia Maria Natália de Souza, "Uma reflexão sobre os discursos menores ou a 
em relação a categorias como autobiografia e autoficção, as quais têm sido mobilizadas pela crítica literária para análise das obras em que uma experiência aparece narrada em possível identidade com a trajetória de quem a assina, Evaristo chama atenção para a matéria viva que inscreve nas malhas da letra epistemes não ocidentais, insubmissas vivências e saberes ancestrais, dando notícias de que "talvez, estas mulheres (como eu) tenham percebido que se o ato de ler oferece a apreensão do mundo, o de escrever ultrapassa os limites de uma percepção da vida". ${ }^{3}$

Ultrapassar os limites de uma percepção da vida parece ser o que Scholastique Mukasonga almeja na obra aqui resenhada, se irmanando à produção dessas e de outras escritoras negras atlânticas. Numa conformação que poderia ser lida como escrevivência, Mukasonga, assim como Anzaldúa ou Evaristo, equilibra-se no pêndulo vida-morte e faz da literatura uma forma de assunção de sua posição no mundo: mulher negra, africana, sobrevivente do genocídio ocorrido em

escrevivência como narrativa subalterna, Revista Crioula, n. 21 (2018), pp. 25-43.

3 Conceição Evaristo, "Da grafia-desenho de minha mãe, um dos lugares de nascimento de minha escrita", in Marcos Antônio Alexandre (org.), Representações performáticas Brasileiras: teorias, práticas e suas interfaces (Belo Horizonte: Mazza, 2007), p. 21. <http://nossaescrevivencia. blogspot.com/2012/08/da-grafia-desenho-de-minha-mae-um-dos.html $>$, acessado em 18/10/2019.
Ruanda, seu país natal, em 1994.

Esse genocídio, ainda que estruture e determine em alguma medida o surgimento do texto, sendo o seu pano de fundo, não é narrado diretamente na obra, a qual se concentra nos anos anteriores ao massacre e, sob a perspectiva tutsi, reelabora o conflito entre tutsis e hutus. A feição étnica dessa tensão, contudo, precisa ser compreendida como resultante de um processo histórico singular. Conforme explica Kabengele Munanga, no período pré-colonial, hutus, tutsis e twas compartilhavam o mesmo território e, mesmo que numa organização social "que os estudiosos consideram de castas, classes ou posições sociais", constituíam unidade cultural e política. ${ }^{4}$ A "raciologia" posta em prática pelos colonizadores belgas, em aliança com a Igreja Católica, porém, além de classificar esses segmentos sociais - instituindo inclusive carteiras de identidade étnicas - reorganizou a sociedade ruandesa de modo a estabelecer uma posição de domínio dos tutsis sobre os hutus. Esse domínio implicou na ocupação dos principais cargos políticos, administrativos e militares e, ademais, em práticas de opressão contra os hutus, como a cobrança de impostos, a coerção a trabalhos forçados e a discriminação institucionalizada nas escolas. O fim do regime

4 Kabengele Munanga, "Identidade étnica, poder e direitos humanos", Thot, n. 80 (2004), p. 22. 
belga, em 1992, deixa como saldo a "etnicidade como traço definidor da existência ruandesa" e o desmantelo total da ideia de identidade nacional.

A escrevivência de Mukasonga, instância narradora do texto, tem como marcador temporal o momento em que hutus, maioria populacional do país, ancorados numa releitura do mito eurocentrado que justificou a supremacia de um grupo sobre o outro, passam a exigir a expulsão dos tutsi - lidos agora como estrangeiros - do território. ${ }^{5}$ Nessa direção, a narrativa permite a nós, leitores, entrever os modos como os tutsis organizaram formas de resistência e sobrevivência durante os anos em que foram perseguidos pelos hutus e forçados ao exílio, quando não nos países vizinhos, Uganda e Burundi, em outras regiões do próprio país. De forma mais específica, as memórias evocadas no texto procuram recuperar e conferir protagonismo à figura da mãe da narradora, Stefania, numa Ruanda em que o ato de dar à luz, até então celebrado socialmente, passa a remeter ao medo:

dizia a minha mãe, as mulheres tinham orgulho de ter filhos. Muitos filhos. Principalmente meninos. Mas, em Nyamata, elas morriam de medo de colocar filhos no mundo. Não por elas, mas pelas crianças. Sobretudo pelos meninos. Elas sabiam que eles seriam

5 Essa "virada" histórica tem como marco o "Manifesto Hutu" de 1957. mortos; que cedo ou tarde seriam mortos. (p. 20)

A história da "Ruanda das mães-coragem", atravessada pela violência e pela dor, é, assim, esteticamente contada. A tensão entre a necessidade de alimentar as tradições, a religiosidade, os costumes locais e as imposições violentas das autoridades hutus implica uma série de deslocamentos e reconfigurações que são agudizadas na narrativa por meio dos recortes de acontecimentos específicos centrados no cotidiano de uma comunidade em desterro. As ações do enredo dão corpo e complexidade a tais constrições, fundindo resiliência, astúcia e solidariedade aos sentimentos de terror que perpassam as experiências reelaboradas na obra, como:

Não sei dizer quantas vezes os soldados foram saquear nossas casas e aterrorizar os moradores. $\mathrm{Na}$ minha lembrança, toda a violência ficou gravada em uma única cena. É como um filme que fica passando e se repetindo. As imagens são sempre as mesmas e alimentam até hoje os meus piores pesadelos $[\ldots]$ $\mathrm{O}$ que primeiro me vem à lembrança é uma cena tranquila. Toda a família está reunida no único cômodo da casa, ao redor das três pedras da lareira $[\ldots]$ E, de repente, o estrondo da placa de metal que serve de porta desabando: só tenho tempo e agarrar minha irmãzinha e deitar com ela no canto para impedir que a bota machuque o ros- 
to dela, a bota que sai pisando as batatas-doces e que amassa o prato de metal no meio como se fosse cartolina [...]. (pp. 10-11).

Diante desse contexto, as estratégias de Stefania para manter viva sua família e a cosmovisão da existência de seu povo, num mundo em que ambas estão ameaçadas, dão corpo aos outros capítulos do livro. Intitulados como "Salvar os filhos", "As lágrimas da lua", "A casa de Stefania", "O sorgo", "Medicina", "O pão", "A beleza e os casamentos", "O casamento de Antoine" e "O país das histórias", esses segmentos permitem ver a riqueza da cultura tutsi por meio das detalhadas descrições do ciclo do cultivo do sorgo e da sabedoria que implica no aproveitamento de todas as suas partes para alimentação, comercialização e realização dos rituais religiosos; da indicação dos códigos de sociabilidade que orientam as etapas de individuação dos sujeitos, sobretudo das mulheres; da caracterização do processos de formação das famílias; e da partilha de narrativas míticas que aquecem a imaginação das crianças em volta das fogueiras.

No âmbito desse repertório que nos é apresentado, constatamos, em diálogo com as proposições de Munanga, que a perseguição operada pelos hutus, responsável por fraturas em todas as práticas socais descritas, é também narrada sob o lastro da mencionada ação colonial belga de dividir para dominar.
A explicitação dessa intervenção torna-se notória quando Mukasonga justapõe o mito de origem tutsi que vigorava no período pré-colonial àquele disseminado pelos colonizadores. Ela, então afirma que, em oposição ao que todos os ruandeses sabiam, isto é, de que "no começo, Kigwa tinha caído do céu com todos os animais domésticos e plantas cultivadas, que Gihanga tinha organizado a sociedade de homens dividindo as tarefas, segundo a disposição de cada um" (p. 122), os brancos

Pretendiam saber melhor do que nós quem éramos e de onde vínhamos. Eles nos apalparam, nos pesaram, nos mediram. As conclusões a que chegaram foram categóricas: nossos crânios eram caucasianos, nossos perfis, semíticos, nossa estatura, nilótica. Eles conheciam até mesmo o nosso ancestral, estava na Bíblia e se chamava Cã. Nós éramos os quase brancos, apesar de algumas mestiçagens repugnantes, um pouco judeus, um pouco arianos. (p. 121)

Sublinhando o fundamento de um conflito que desembocou num dos maiores genocídios da humanidade e permaneceu fora dos holofotes da parte ocidentalizada do planeta, Mukasonga, ainda que em língua desconhecida por sua mãe, tal como a narradora afirma, faz da sua escrevivência uma possibilidade de caminhar pelo terreno quebradiço do passado. As estatís- 
ticas divergem: $500 \mathrm{mil}, 800 \mathrm{mil}$, mais de um milhão, são estes os números de pessoas assassinadas no massacre realizado pelos hutus contra os tutsis, em 1994. As mulheres que não foram mortas, foram estupradas. Como sobrevivente que teve quase toda a família exterminada, a autora investe a sua literatura da potência de, em correspondência com o que indica Márcio Seligmann-Silva ao analisar relatos de situações traumáticas de perdas, conectar-se com a memória dos que não sobreviveram e buscar dar túmulo a eles. ${ }^{6}$ Nesse contínuo, a riqueza da obra também reside nas formas como mãe e filha mutuamente se constituem por uma linguagem que consegue revestir de afeto e poeticidade a vida subsistente.

Stefania figura como imagem de força, sabedoria e resiliência. Elemento determinante para a trajetória de Mukasonga que, desde a Europa, ancora-se na memória-presença dessa mãe para operar sua caminhada, de pés descalços, por entre os esqueletos esquecidos da história. Narrando desde o trauma, as memórias infanto-juvenis tornam-se, assim, prisma para uma possível elaboração identitária da narradora, que se apresenta, contudo, literariamente cifrada para nós leitores:

De todas as partes do corpo, os pés eram os mais expostos aos machu-

6 Seligmann-Silva apud Jaime Ginzburg, Crítica em tempos de violência, São Paulo: Edusp/Fapesp, 2012, p. 54. cados. Caminhávamos descalços e, ao voltar para casa depois da aula, ainda íamos buscar água ou lenha seca e, em geral, éramos surpreendidos, no caminho de volta pela noite que, em Ruanda, chega sempre, em qualquer época do ano, às seis da tarde. [...] Ao chegar em casa, meus pés estavam sangrando, as unhas quebradas, arrancadas [...] "Alexia tem dedos que enxergam, dizia mamãe. Já os seus e os de Julienne (pois os pés de Julienne ficavam no mesmo estado em que os meus) não veem nada, mas vou ensiná-los a ver". E, depois do jantar no breu da noite, Stefania tentava ensinar nossos dedos do pé a enxergar. Ela fabricava uma tocha com galhos secos e varria o chão com a chama bem na frente dos nossos dedos. Ela dizia a eles, principalmente aos dedões que ficavam mais expostos aos perigos da estrada: "Abram os olhos". Mas os dedos do pé insistiam em não ver nada, os olhos do dedo não se abriam. Mamãe não desanimava, ela me aconselhava: "Quando você estiver caminhando, deve se dirigir ao coração, ele vai espalhar luz por todo o seu corpo. Assim, diga a ele para se lembrar aos dedos do pé para olharem por onde pisam" $[\ldots]$ Mas não adiantava, meus dedos não queriam ouvir [...] Eles permaneceram fechados para sempre. (pp. 60-61)

Preenche-se o branco do papel, desvela-se o silêncio da história por meio de uma mortalha de pa- 
lavras tecidas, uma a uma, com a precisão e o refinamento do artefato artístico. Em consonância com a conclamação de Anzaldúa, A mulher de pés descalços conforma uma dicção poética que projeta como uma narrativa singular a voz de um conjunto de mulheres negras, mães, subalternizadas na lógica racista do sistema-mundo contemporâneo, Mukasonga, em companhia dessas mulheres, exige deferência a suas memórias e, ao interpelar nossa companhia para cobrir o corpo de seus mortos, conduz-nos ao mais profundo questionamento ético desse mundo e de nós mesmas(os).

Fabiana Carneiro da Silva fabicarneirodasilva@yahoo.com.br Universidade Federal do Sul da Bahia 